American Journal of Applied Sciences 6 (2): 224-232, 2009

ISSN 1546-9239

(C) 2009 Science Publications

\title{
The Analysis of a prismatic Beam Made of Physical Nonlinear Material under Concentrated and Distributed Continuous Moving Loads
}

\author{
Esfandiar Mardani \\ Department of Civil Engineering, Urmia University, Urmia, Iran
}

\begin{abstract}
It is assumed that a beam made of material has a physical nonlinear behavior. This beam is analyzed under the moving concentrated and distributed continuous loads. The vibration equations of motion are derived from the Hamilton's Principle and Euler-Lagrange Equation. In this study, the amplitude of vibration, circular frequency, bending moment, stress and deflection of the beam has been calculated. At the state of concentrated moving load, the obtained analytic solution has been exemplified. The results of this study indicate that when the material of the beam is considered physically nonlinear, there is no critical velocity and the resonance phenomenon doesn't happen.
\end{abstract}

Keywords: Moving load, hamilton principle, euler- lagrange equation, duffing equation, resonance

\section{INTRODUCTION}

The study of dynamical effect of moving loads at highway and railroad bridges has a history of more than one and a half century. The collapse of Jester Bridge in England in 1847 encouraged both the theoretical and experimental studies. The catastrophe caused tremendous human losses and created a lot of excitement in civil engineering (Bussinesk, 1883; Cox, 1850; O-More, 1868; Stokes, 1849; Vinkler, 1868; Willis, 1849, as cited in Glushkov 1974 and Krolov, 1905, as cited in Kesiliev, 1969).

Presently, there are many structures made from materials which are not subject to the Hook's law. Therefore, there is a great tendency to study stress and strain in elements of structures made of physical nonlinear material under various static and dynamic loads. In the linear theory, the property of material is not taken into consideration; However, all of relevant parameters are taken into consideration in the theory of nonlinear. Thus, the physical nonlinear theory at small deformations demonstrates an exact calculation method for the analysis of stress, strain and other internal forces in structural elements.

In order to represent all the possible states of the material by one mathematical law, the following algebraic function may be introduced:

$$
\sigma=\alpha_{1} \varepsilon+\alpha_{2} \varepsilon^{2}+\alpha_{3} \varepsilon^{3}+\ldots
$$

This expression is not different from the general relationship between $\sigma$ and $\varepsilon$.

$$
\sigma=\mathrm{f}(\varepsilon)
$$

Manzhaalovsky (as cited in Glushkov, 1974) employed Empeher's method and proposed the following two-term formulas of the parabolic type on the basis of the tests carried out by. Stolyarov and Skramtayev (as cited in Glushkov, 1974).

$$
\begin{aligned}
& \sigma_{1}=\alpha_{1} \varepsilon-\beta_{1} \varepsilon^{2} \text { (for compression) } \\
& \sigma_{2}=\alpha_{2} \varepsilon-\beta_{2} \varepsilon^{2} \text { (for tension) }
\end{aligned}
$$

Where $\alpha_{1}, \alpha_{2}, \beta_{1}$ and $\beta_{2}$ are empire elasticity. Trinomial formulas of the parabolic type were suggested for cast iron by Hodgkinson (1822, as cited in Glushkov, 1974) and Cox (1850 as cited in Glushkov, 1974). Type (as cited in Glushkov, 1974) proposed the use of a similar relationship for metal wire:

$$
\varepsilon=\alpha \sigma+b \sigma^{2}+c \sigma^{3}
$$

In addition to exponential and power laws, hyperbolic relationships were suggested for brittle materials. Accordingly, Cox introduced the following function for cast iron:

$$
\varepsilon=\frac{\sigma}{\alpha-b \sigma}
$$

Grubler, schlechtwg and Deither (as cited in Glushkov, 1974), who developed a theory for bars and discs made of brittle materials, employed the following hyperbolic laws: 
Am. J. Applied Sci., 6 (2): 224-232, 2009

$$
\begin{aligned}
\sigma & =\frac{\sigma}{\mathrm{A}+\mathrm{B \varepsilon}} \\
\varepsilon & =\frac{\sigma}{\mathrm{E}} \frac{1}{1-\alpha \sigma+\beta \sigma \sqrt{\sigma}}
\end{aligned}
$$

Finally, the relationship between stress and strain, in the case of physical nonlinear, is presented by Kauderer (1961). As the formula proposed by Kauderer is comprehensive and expresses the relationship between the stress and strain in three dimensional state, we preferred to use the formula for the analysis of the physical nonlinear stress and strain.

$$
\begin{aligned}
& \varepsilon_{\mathrm{ij}}=\frac{\mathrm{K}\left(\sigma_{0}\right)}{3 \mathrm{~K}} \sigma_{0}+\frac{1\left(\mathrm{t}_{0}^{2}\right)}{2 \mathrm{G}}\left(\sigma_{\mathrm{ij}}-\sigma_{0} \partial_{\mathrm{ij}}\right) \\
& \mathrm{i}, \mathrm{j}=1,2,3
\end{aligned}
$$

Where $\partial_{\mathrm{ij}}$ is Croneker symbols and $\sigma_{0}$ is average stress:

$$
\sigma_{0}=\frac{\sigma_{x}+\sigma_{y}+\sigma_{z}}{3}
$$

$\mathrm{K}$ and $\mathrm{G}$ at small deformation are respectively volume contraction and shear elastic module. The relationship among $\mathrm{K}, \mathrm{E}$ and $\mathrm{G}$ is indicated through the following formula:

$$
E=\frac{9 K G}{5 K+G}
$$

$\mathrm{K}\left(\sigma_{0}\right)$ is average stress function and $1\left(\mathrm{t}_{0}^{2}\right)$ is shear stress function, it can be indicated through the following expression:

$$
\begin{aligned}
& \mathrm{K}\left(\sigma_{0}\right)=1+\mathrm{K}_{1} \sigma_{0}+\mathrm{K}_{2} \sigma_{0}^{2}+\ldots=\sum_{\mathrm{n}=0}^{\infty} \mathrm{K}_{\mathrm{n}} \sigma_{0}^{\mathrm{n}} \\
& \mathrm{l}\left(\mathrm{t}_{0}^{2}\right)=1+\mathrm{l}_{2} \mathrm{t}_{0}^{2}+\mathrm{l}_{4} \mathrm{t}_{0}^{4}+\ldots=\sum_{\mathrm{n}=0}^{\infty} \mathrm{l}_{2 \mathrm{n}} \mathrm{t}_{0}^{2 \mathrm{n}}
\end{aligned}
$$

Researches have demonstrated that $\mathrm{K}\left(\sigma_{0}\right)$ in physical nonlinear material on an average relative deformation is close to the straight line (i.e., $\mathrm{K}$ $\left.\left(\sigma_{0}\right)=1\right)$. Also, the two first sentences of the shear stress function are enough.

$$
1\left(t_{0}^{2}\right)=1+1_{2} t_{0}^{2}
$$

In the above expression, $l_{2}$ is the physical nonlinear coefficient.
As the formula (9) indicates, stress components of $\sigma_{\mathrm{z}}, \sigma_{\mathrm{y}}$ and $\sigma_{\mathrm{xy}}$ are created. The simplification of the formula suggests that the stress components are too small in comparison with the $\sigma_{\mathrm{Z}}$. These new components of the stress have less impact on the frequency of vibration and on the other parameters during the vibration of the beam. As a result, the following formula is obtained from the formula (9) at a two dimensional surface:

$$
\sigma_{\mathrm{Z}}=\mathrm{E}\left(\varepsilon_{\mathrm{Z}}-\frac{2}{27} 1_{2} \frac{\mathrm{E}^{3}}{\mathrm{G}^{3}} \varepsilon_{\mathrm{Z}}^{3}\right)
$$

The purpose of this paper was the analysis of a beam made of physical nonlinear material under the moving concentrated and distributed continuous loads, which was discussed through examples analytically.

Analytical solution for moving concentrated load: To study the effect of moving load on the prismatic beam, first, we are discussing moving concentrated load. Thus, it is assumed that the load $\mathrm{P}$ moves along the beam (Fig. 1).

To consider the effect of external moving load, it is assumed an equivalent distributed load which depends on $\mathrm{z}$ and $\mathrm{t}$ as follows:

$$
q(z, t)=\sum_{k=1}^{\infty} \frac{2 P}{L} \sin \frac{k \pi a}{L} \sin \frac{k \pi z}{L}
$$

Where, $\mathrm{p}(\mathrm{z})=\sin \frac{\mathrm{k} \pi \mathrm{z}}{\mathrm{L}}, \quad(\mathrm{k}=1,2,3, \ldots)$ is the head vibration mode of the beam.

Therefore, the potential and kinetic energy of the system will be as follows:

$$
\begin{aligned}
& \Pi=\int_{0}^{L}\left[\frac{1}{2} J_{0} E\left(\frac{\partial^{2} w}{\partial z^{2}}\right)^{2}-\frac{1}{54} l_{2} \frac{E^{4}}{G^{3}} J_{1}\left(\frac{\partial^{2} w}{\partial z^{2}}\right)^{4}\right] d z \\
& K i=\frac{1}{2} \rho F \int_{0}^{L}\left(\frac{\partial w}{\partial t}\right)^{2} d z
\end{aligned}
$$

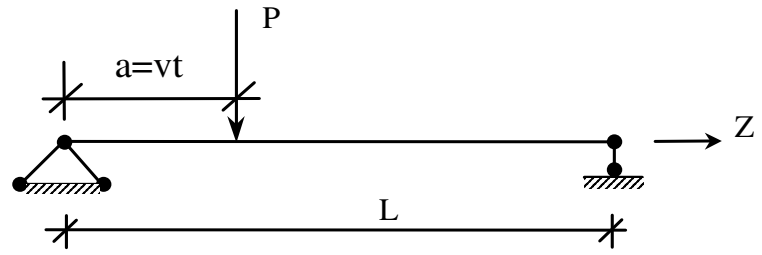

Fig. 1: Schematic view of a prismatic beam under moving load 
Also, the work of the external moving load will be as follows:

$$
\begin{aligned}
& A=\int_{0}^{L} q(z, t) \cdot w(z, t) d z \\
& A=\frac{2 P}{L} \int_{0}^{L} \sum \sin \frac{k \pi a}{L} \sin \frac{k \pi z}{L} w(z, t) d z
\end{aligned}
$$

The Hamilton's Principle for this beam will be expressed as below:

$$
\begin{aligned}
& \mathrm{H}=\int_{\mathrm{t} 1}^{\mathrm{t} 2}(\Pi-\mathrm{A}-\mathrm{Ki}) \mathrm{dt}=\int_{\mathrm{t} 1}^{\mathrm{t} 2} \int_{0}^{\mathrm{L}}\left[\frac{1}{2} \mathrm{~J}_{0} \mathrm{E}\left(\frac{\partial^{2} \mathrm{w}}{\partial \mathrm{z}^{2}}\right)^{2}-\right. \\
& \frac{1}{54} \mathrm{l}_{2} \frac{\mathrm{E}^{4}}{\mathrm{G}^{3}} \mathrm{~J}_{1}\left(\frac{\partial^{2} \mathrm{w}}{\partial \mathrm{z}^{2}}\right)^{4}-\frac{2 \mathrm{P}}{\mathrm{L}} \sum_{\mathrm{k}=1}^{\infty} \sin \frac{\mathrm{k} \pi \mathrm{a}}{\mathrm{L}} \sin \frac{\mathrm{k} \pi \mathrm{a}}{\mathrm{L}} \mathrm{w}(\mathrm{z}, \mathrm{t})- \\
& \left.\frac{1}{2} \rho \mathrm{F}\left(\frac{\partial \mathrm{w}}{\partial \mathrm{t}}\right)^{2}\right] \mathrm{dz} . \mathrm{dt}
\end{aligned}
$$

Where: $\mathrm{J}_{0}=\iint \mathrm{y}^{2} \mathrm{dxdy}, \mathrm{J}_{1}=\iint \mathrm{y}^{4} \mathrm{dxdy}$ Considering:

Which varies respectively from 0 to $\pi$ and 0 to $2 \pi$, where is circular frequency vibration of the system in linear case and expressing in Hamilton principle (19), the following formulas are obtained:

$$
\begin{aligned}
& \mathrm{H}=\frac{\mathrm{L}}{\pi \omega_{0}} \iint\left\{\frac{1}{2} \mathrm{~J}_{0} \mathrm{E} \frac{\pi^{4}}{\mathrm{~L}^{4}}\left(\frac{\partial^{2 \mathrm{w}}}{\partial \zeta^{2}}\right)^{2}\right. \\
& -\frac{1}{54} \frac{\mathrm{E}^{4}}{\mathrm{G}^{3}} \mathrm{~J}_{1} \frac{\pi^{8}}{\mathrm{~L}^{8}}\left(\frac{\partial^{2} \mathrm{w}}{\partial \zeta^{2}}\right)^{4}-\frac{2 \mathrm{P}}{\mathrm{L}} \sum_{\mathrm{k}=1}^{\infty} \sin \mathrm{k} \zeta_{0} \\
& \left.\sin \mathrm{k} \zeta \cdot \mathrm{w}(\zeta, \tau)-\frac{1}{2} \rho \mathrm{F} \omega_{0}^{2}\left(\frac{\partial \mathrm{w}}{\partial \mathrm{t}}\right)^{2}\right\} \mathrm{d} \zeta . \mathrm{d} \tau
\end{aligned}
$$

We assumed that the deformation of the beam would be found from the following expression:

$$
\mathrm{w}(\zeta, \tau)=\mathrm{p}(\zeta) \cdot \mathrm{q}(\tau)
$$

Where, $\mathrm{p}(\xi)$ and $\mathrm{q}(\tau)$ are coordinate and generalized functions respectively.

By substitution of expression (21) in expression (20), we obtain the following expressions:

$$
\begin{aligned}
& \mathrm{H}=\frac{\mathrm{L}}{\pi \omega_{0}} \int_{0}^{2 \pi} \int_{0}^{\pi}\left\{\frac{1}{2} \mathrm{~J}_{0} \mathrm{E} \frac{\pi^{4}}{\mathrm{~L}^{4}}\left[\mathrm{p}^{\prime \prime}(\zeta)\right]^{2} \cdot \mathrm{q}^{2}\right. \\
& -\frac{1}{54} \mathrm{l}_{2} \frac{\mathrm{E}^{4}}{\mathrm{G}^{3}} \mathrm{~J}_{1} \frac{\pi^{8}}{\mathrm{~L}^{8}} \mathrm{p}^{\prime \prime} \cdot \mathrm{q}^{4}- \\
& \frac{2 \mathrm{P}}{\mathrm{L}} \sum_{\mathrm{k}=1}^{\infty} \sin \frac{\mathrm{k} \pi \mathrm{vt}}{\mathrm{L}} \sin \mathrm{k} \zeta \cdot \mathrm{p}(\zeta) \cdot \mathrm{q}(\tau)- \\
& \left.\frac{1}{2} \rho \mathrm{F} \omega_{0}^{2} \mathrm{p}^{2}(\zeta) \cdot \mathrm{q}^{2}\right\} \mathrm{d} \zeta \cdot \mathrm{d} \tau
\end{aligned}
$$

The following expression is derived from the calculations indicated above in (22):

$$
\mathrm{H}=\frac{\mathrm{L}}{\pi \omega_{0}} \int_{0}^{2 \pi}\left\{\begin{array}{l}
a q^{2}+b q^{4}- \\
c \omega_{0}^{2} q^{\prime 2}-d^{\prime} q
\end{array}\right\} d \tau=\frac{L}{\pi \omega_{0}} \int_{0}^{2 \pi} N d \tau
$$

Where:

$$
\begin{aligned}
& \mathrm{a}=\frac{1}{2} \mathrm{~J}_{0} \mathrm{E} \frac{\pi^{4}}{\mathrm{~L}^{4}} \int_{0}^{\pi} \mathrm{p}^{\prime \prime 2} \mathrm{~d} \zeta \\
& \mathrm{b}=-\frac{1}{54} \mathrm{l}_{2} \frac{\mathrm{E}^{4}}{\mathrm{G}^{3}} \mathrm{~J}_{1} \frac{\pi^{8}}{\mathrm{~L}^{8}} \int_{0}^{\pi} \mathrm{p}^{\prime \prime 4} \mathrm{~d} \zeta \\
& \mathrm{c}=\frac{1}{2} \rho \mathrm{F} \int_{0}^{\pi} \mathrm{p}^{2}(\zeta) \mathrm{d} \zeta \\
& \mathrm{d}=\frac{\pi \mathrm{P}}{\mathrm{L}} \sin \frac{\mathrm{k} \pi \mathrm{vt}}{\mathrm{L}}
\end{aligned}
$$

For Integral (23), Euler formula gives:

$$
\begin{aligned}
& \frac{\partial}{\partial \tau}\left(\frac{\partial N}{\partial q}\right)-\frac{\partial N}{\partial q}=0 \\
& \frac{\partial}{\partial \tau}\left(-2 c \omega_{0}^{2} q^{\prime}\right)=-2 c \omega_{0}^{2} q^{\prime \prime} \\
& \frac{\partial N}{\partial q}=2 a q+4 b q^{3}-d^{\prime} \\
& -2 c \omega_{0}^{2} q^{\prime \prime}-2 a q-4 b q^{3}+d^{\prime}=0 \\
& -2 c \omega_{0}^{2} q^{\prime \prime}-2 a q\left(1+2 \frac{b}{a} q^{2}\right)= \\
& d^{\prime}=\frac{\pi P}{L} \sin \frac{k \pi v t}{L}
\end{aligned}
$$

By substitution of $\theta=\frac{k \pi v}{L}, t=\frac{\tau}{\omega_{0}}$ into equation (26) we'll have:

$$
\omega_{0}^{2} q^{\prime \prime}+\frac{a}{c} q\left(1+2 \frac{b}{a} q^{2}\right)=d \sin \eta \tau
$$

Where:

$$
\eta=\frac{\theta}{\omega_{0}}, d=\frac{\pi P}{2 c L}
$$

By substitution of $X=\frac{\omega_{0}^{2}}{d} q$ into equation (27), we'll have:

$$
\mathrm{X}^{\prime \prime}+\mathrm{X}\left(1+\mathrm{e} \mathrm{X}^{2}\right)=\sin \eta \tau
$$


Where:

$$
\mathrm{e}=2 \frac{\mathrm{b}}{\mathrm{a}} \frac{\mathrm{d}^{2}}{\omega_{0}^{4}}
$$

To solve the Duffing Equation (28), we follow the following procedure:

$$
\begin{aligned}
& X=\sum_{n=1,3,5 \ldots}^{\infty} X_{n} \sin \eta \tau=X_{1} \sin \eta \tau+ \\
& X_{3} \sin 3 \eta \tau+X_{5} \sin 5 \eta \tau+\ldots
\end{aligned}
$$

If we substitute the expression (30) into 28 and compare the similar coefficients of $\sin n \eta \tau$, we will get a lot of cubic nonlinear algebraic equations. To our knowledge, there is no exact solution for these equations. Thus, we employed an approximated method. For this purpose, we applied three constraints equation (30) and we assumed that $X_{n} \gg X_{n+1}$ : therefore, in this case, we will have the following system of nonlinear equations :

$$
\begin{aligned}
&\left(1-\eta^{2}\right) X_{1}+e\left(\frac{3}{4} X_{1}^{3}+\frac{3}{2} X_{1} X_{3} X_{5}+\frac{3}{4} X_{1}^{2} X_{3}+\right.\left.\frac{3}{2} X_{1} X_{3}^{2}+\frac{3}{4} X_{3}^{2} X_{5}+\frac{3}{2} X_{1} X_{5}^{2}\right)=1 \\
&\left(1-9 \eta^{2}\right) X_{3}+e\left(\frac{1}{11} X_{1}^{3}+\frac{3}{4} X_{3}^{3}+\frac{3}{2} X_{1} X_{3} X_{5}+\right. \\
&\left.\frac{3}{2} X_{1}^{2} X_{3}+\frac{3}{2} X_{3} X_{5}^{2}+\frac{3}{4} X_{1}^{2} X_{5}\right)=0 \\
&\left(1-25 \eta^{2}\right) X_{5}+e\left(\frac{3}{4} X_{5}^{3}+\frac{3}{4} X_{1}^{2} X_{3}+\frac{3}{4} X_{1} X_{3}^{2}+\right. \\
&\left.\frac{3}{2} X_{3}^{2} X_{5}+\frac{3}{2} X_{1}^{2} X_{5}\right)=0
\end{aligned}
$$

By solving of Eq. (31) by the method of Zeidel, we will have:

$$
\begin{aligned}
& \left(1-\eta^{2}\right) X_{1}+\frac{3}{4} \mathrm{eX}_{1}^{3}=1 \\
& \mathrm{X}_{3}=\frac{\mathrm{ex}_{1}^{3}}{4\left(9 \eta^{2}-1\right)} \\
& \mathrm{X}_{5}=\frac{3 \mathrm{ex}_{1} \mathrm{X}_{3}\left(\mathrm{X}_{1}+\mathrm{X}_{3}\right)}{4\left(25 \eta^{2}-1\right)}
\end{aligned}
$$

When the load is out of the beam, Exp. (27) will be as below in which the system will have free vibration.

$$
\frac{d q^{2}}{d \tau^{2}}+\frac{a}{\omega^{2} c} q\left(1+2 \frac{b}{a} q^{2}\right)=0
$$

Finally, by solving equation (33), we found the period of vibration:

$$
\mathrm{T}=4 \cdot \frac{\omega}{\sqrt{\frac{\mathrm{a}}{\mathrm{c}}\left(1+\frac{\mathrm{b}}{\mathrm{a}} \mathrm{Q}^{2}\right)}} \cdot \mathrm{k}(\bar{\theta})
$$

Consequently, the circular frequency is as follows:

$$
\omega=\frac{\pi}{2} \sqrt{\frac{\mathrm{a}}{\mathrm{c}}\left(1+\frac{\mathrm{b}}{\mathrm{a}} \mathrm{Q}^{2}\right)} \cdot \frac{1}{\mathrm{~K}(\bar{\theta})}
$$

Where:

$$
\mathrm{K}(\bar{\theta})=\frac{\pi}{2}\left[1+\frac{1}{4} \sin ^{2} \bar{\theta}+\frac{9}{64} \sin ^{4} \bar{\theta}+\frac{25}{256} \sin ^{6} \bar{\theta}+\ldots\right]
$$

$\omega$ is the circular frequency of vibration, $Q$ is amplitude of vibration and $\mathrm{k}(\bar{\theta})$ is a second order elliptic integral. As the above formula indicates, $\frac{b}{a} Q^{2}$ has a minus sign, which decreases the $\omega$ in comparison with $\omega_{0}$ (as it was indicated in 35).

Based on the equations expressed above, the explanation of the analysis of deflection, bending stress and bending moment are as follows.

Deflection: Deflection is obtained from the Eq. (21).

$$
\begin{aligned}
& \mathrm{W}(\mathrm{z}, \mathrm{t})=\frac{\mathrm{d}}{\omega^{2}} \sin \frac{\pi \mathrm{z}}{1} \sum_{\mathrm{n}=1,3,5} \mathrm{X}_{\mathrm{n}} \sin \frac{\mathrm{n} \pi \mathrm{a}}{1} \\
& \sum_{\mathrm{n}=1,3,5} \mathrm{X}_{\mathrm{n}} \sin \frac{\mathrm{n} \pi \mathrm{a}}{1}=\mathrm{X}_{1} \sin \frac{\pi \mathrm{a}}{1}+ \\
& \mathrm{X}_{3} \sin \frac{3 \pi \mathrm{a}}{1}+\mathrm{X}_{5} \sin \frac{5 \pi \mathrm{a}}{1} \mathrm{a}=\mathrm{Vt} \\
& \text { and } \frac{\mathrm{d}}{\omega^{2}}=\frac{\mathrm{Pl}^{3}}{\mathrm{EJ}_{0} \pi^{3} \int\left[\mathrm{p}^{\prime \prime}(\zeta)\right]^{2} \mathrm{~d} \zeta}
\end{aligned}
$$

As it will be indicated in the tables below, the Coefficients $\mathrm{X}_{3}$ and $\mathrm{X} 5$ are too small and neglected.

$$
\mathrm{W}(\mathrm{z}, \mathrm{t})=\frac{\mathrm{d}}{\omega^{2}} \mathrm{X}_{1} \sin \frac{\pi \mathrm{z}}{1} \sin \frac{\pi \mathrm{a}}{1}
$$

Bending Stress: Bending Stress is Calculated by using 


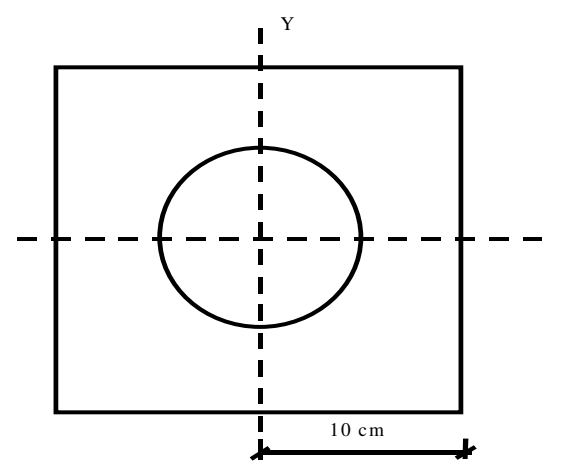

Fig. 2: Section of beam

Eq. (14) and $\varepsilon_{z}=y \frac{\partial^{2} w}{\partial z^{2}}$ which is called KIRHOF principle.

$$
\sigma_{z}=E\left[y \frac{\partial^{2} w}{\partial z^{2}}-\frac{2}{27} l_{2} \frac{E^{3}}{G^{3}}\left(y \frac{\partial^{2} w}{\partial z^{2}}\right)^{3}\right]
$$

Bending Moment: Bending Moment in every section of the beam is designed by the following equations:

$$
\begin{aligned}
& M=\iint \sigma_{z} y d x d y=E \iint\left[y \frac{\partial^{2} w}{\partial z^{2}}-\frac{2}{27} l_{2} \frac{E^{3}}{G^{3}}\left(y \frac{\partial^{2} w}{\partial z^{2}}\right)\right] d x d y \\
& M=E j_{0} \frac{\partial^{2} w}{\partial z^{2}}\left[1-\frac{2}{27} l_{2} \frac{E^{3}}{G^{3}} \cdot \frac{J_{1}}{J_{0}}\left(\frac{\partial^{2} w}{\partial z^{2}}\right)\right]
\end{aligned}
$$

The expression $\frac{\partial^{2} w}{\partial z^{2}}$ equals the following expression:

$$
\frac{\partial^{2} \mathrm{w}}{\partial \mathrm{z}^{2}}=-\frac{\mathrm{d}}{\omega_{0}^{2}} \cdot \frac{\pi^{2}}{1^{2}} \sin \frac{\pi \mathrm{z}}{\mathrm{l}} \sin \frac{\pi \mathrm{a}}{1}
$$

Now the obtained analytic solutions are being applied to the following example. It has been assumed that the material of the beam is copper (Fig. 2).

$$
\begin{aligned}
& \mathrm{J}_{0}=1.236 \times 10^{4} \\
& \mathrm{~J}_{1}=58.44 \times 10^{4} \mathrm{~cm}^{6} \\
& \mathrm{G}=0.46 \times 10^{6} \mathrm{~kg} \mathrm{~cm}^{-2} \\
& \mathrm{E}=1.241 \times 10^{6} \mathrm{~kg} \mathrm{~cm}^{-2} \\
& \mathrm{l}_{2}=0.18 \times 10^{6}, \mathrm{~L}=2 \mathrm{~m}, \mathrm{P}=20 \mathrm{KN}
\end{aligned}
$$

Then vibration amplitudes are determined and are shown in Table 1.

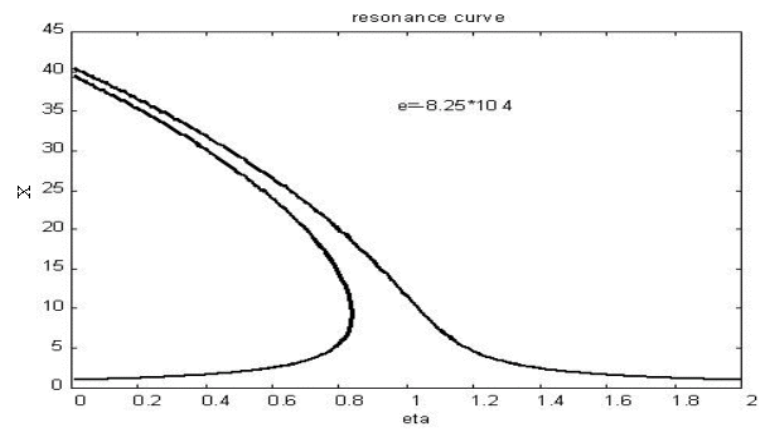

Fig. 3: Resonance curve

Table 1: Dimensionless vibration amplitudes

\begin{tabular}{llllll}
\hline$\eta^{2}$ & $\mathrm{X}^{1}$ & \multicolumn{3}{l}{} \\
& $\mathrm{X}_{1}{ }_{1}$ & $\mathrm{X}_{2}{ }_{2}$ & $\mathrm{X}_{3}{ }_{3}$ & & $\mathrm{X}_{5}$ \\
& -70.83 & 69.83 & 1.00 & -23.94 & \\
\hline 0.0 & -27.04 & 13.52 & & 0.1902 & $-1.31 \times 10^{-3}$ \\
0.889 & -17.03 & & & 0.041 & $-1.01 \times 10^{-4}$ \\
1 & 1.00 & & & $3.69 \times 10^{-6}$ & $-1.63 \times 10^{-11}$ \\
2 & & & & & \\
\hline
\end{tabular}

Based on Table (1) the diagram of resonance is indicated in Fig. 3.

Deflection, stress and bending moment in the section of the beam are calculated by using formulas (36), (37) and (38) for $\eta^{2}=1$ and $\mathrm{z}=\mathrm{a}$, which are indicated in Table 2 and 3.

Bending stress in the middle section of the beam is indicated in Fig. 4.

The Critical velocity for given example is obtained $135.95 \mathrm{~m} / \mathrm{s}$ Dynamical Coefficients according to velocity is obtained and are written in Table 4.

Dynamic Coefficients at linear state are derived by the formula given by Krolov (1905).

$$
\mu=\frac{1}{1-\beta^{2}}\left[1-\left(\beta \sin \frac{\pi \mathrm{a}}{\beta 1} \sin \frac{\pi \mathrm{a}}{1}\right)\right]
$$

Where:

$$
\mathrm{a}=\mathrm{vt}, \quad \beta=\frac{\theta}{\omega}, \quad \theta=\frac{\pi \mathrm{v}}{1}
$$

The Dynamical Coefficient when the load is in the middle of the Span, $a=\frac{1}{2}$ is estimated and shown at Fig. 5.

Based on $\mathrm{v}=50 \mathrm{~m} \mathrm{~s}^{-1},\left(\mathrm{v}=180 \mathrm{~km} \mathrm{~h}^{-1}\right)$, deflection, bending moment and bending stress in the middle of the span are found by the obtained formulas for nonlinear state and for linear state they are found by formulas which are given by Kerolov (1905 as cited in Kesiliev, 1969 ): 
Am. J. Applied Sci., 6 (2): 224-232, 2009

Table 2: Calculation of deflection and bending moment at the point of load

\begin{tabular}{llllllll}
\hline a & $\frac{1}{8}$ & $\frac{1}{4}$ & $3 \frac{1}{8}$ & $\frac{1}{2}$ & $5 \frac{1}{8}$ & $3 \frac{1}{4}$ & $7 \frac{1}{8}$ \\
\hline W (cm) & -0.054 & -0.1856 & -0.3468 & -0.3712 & -0.316 & -0.1856 & -0.054 \\
M (K.N.m) & 2.057 & 6.842 & 11.922 & 14.05 & 11.922 & 6.842 & 2.057 \\
\hline
\end{tabular}

Table 3: Stress in the middle section of the beam

\begin{tabular}{lllll}
\hline $\mathrm{Y}(\mathrm{cm})$ & 6.61 & 7.9676 & 8.9816 & 10 \\
$\sigma_{2}(\mathrm{mpa})$ & 1150 & 1320 & 1422 & 1500.0 \\
\hline
\end{tabular}

Table 4: Dynamical Coefficients

\begin{tabular}{llllllll}
\hline $\mathrm{V}(\mathrm{m} / \mathrm{s})$ & 0 & 25 & 50 & 75 & 100 & 124.57 & 135.95 \\
\hline
\end{tabular}

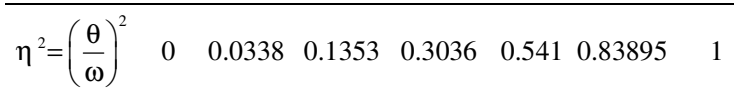
$\mathrm{X}$

$\begin{array}{lllllll}1 & 1.036 & 1.158 & 1.438 & 2.193 & 9.27 & 11.73\end{array}$

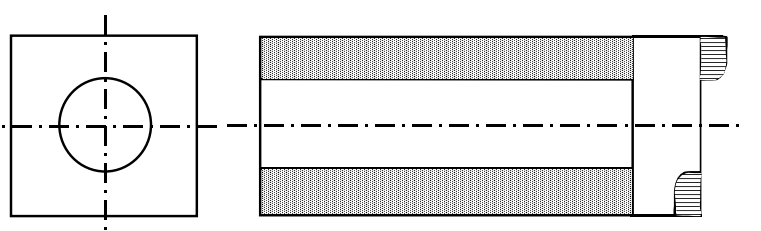

Fig. 4: The diagram of stress in the middle section of the beam

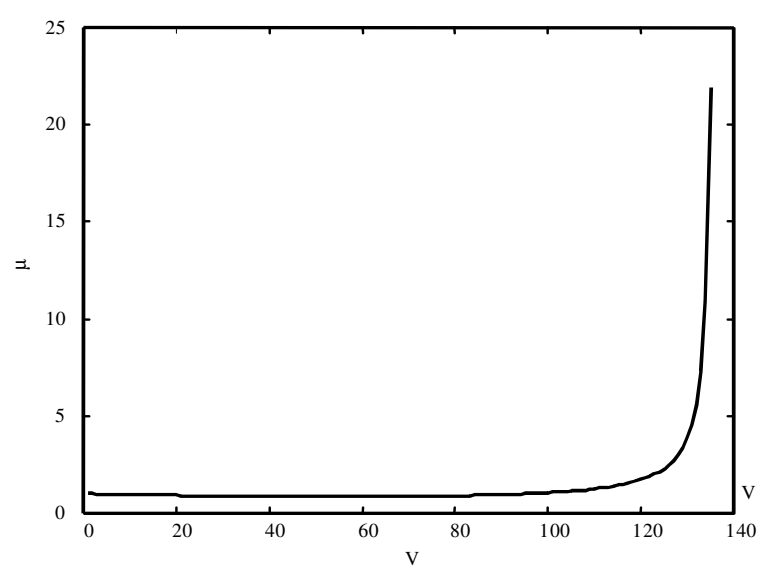

Fig. 5: Dynamical coefficient-velocity

$$
\begin{aligned}
& \mathrm{y}=\frac{\mathrm{p} \delta}{1-\beta^{2}}\left(\sin \cdot \frac{\pi \mathrm{a}}{1}-\beta \sin \frac{1}{\beta} \frac{\pi \mathrm{a}}{1}\right) \\
& \mathrm{M}=\frac{2 \mathrm{pl}}{\pi^{2}} \frac{\sin \cdot \frac{\pi \mathrm{a}}{1}}{\left(1-\beta^{2}\right)}\left(\sin \cdot \frac{\pi \mathrm{a}}{1}-\beta \sin \cdot \frac{\pi \mathrm{a}}{\beta 1}\right)
\end{aligned}
$$

The numerical resultants have written at Table 5 .

Analytical solution for moving distributed load: To consider the effect of moving distributed continuous
Table 5: A comparison of deflection, stress, and bending moment at

\begin{tabular}{llll}
\multicolumn{3}{c}{ linear and nonlinear state } \\
\hline State & $\mathrm{W}(\mathrm{cm})$ & $\sigma(\mathrm{mpa})$ & $\mathrm{M}_{(\mathrm{KN} . \mathrm{M})}$ \\
\hline Nonlinear & 0.025 & 7.73 & 9.5 \\
Linear & 0.034 & 10.29 & 12.48 \\
\hline
\end{tabular}

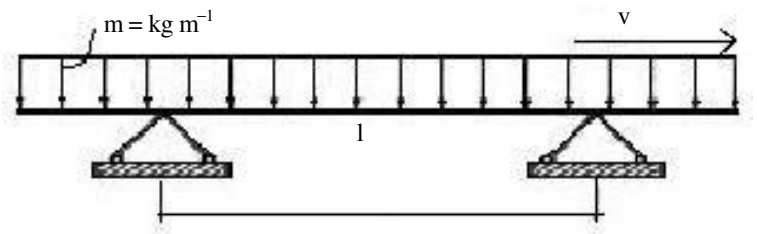

Fig. 6: Schematic view of a prismatic beam under moving load

load, it is assumed that the moving distributed continuous load moves along the prismatic beam as it is shown in Fig.6.

The potential and kinetic energy of this system can be written as follows.

$$
\Pi=\int_{0}^{1}\left[\frac{1}{2} \mathrm{EI}_{0}\left(\frac{\partial^{2} \mathrm{w}}{\partial \mathrm{z}^{2}}\right)^{2}-\frac{1}{54} \mathrm{l}_{2} \frac{\mathrm{E}^{4}}{\mathrm{G}^{3}} \mathrm{I}_{1}\left(\frac{\partial^{2} \mathrm{w}}{\partial \mathrm{z}^{2}}\right)^{4}\right] \mathrm{dz}
$$

and:

$$
\mathrm{ki}=\frac{1}{2} \rho \mathrm{F} \int_{0}^{1}\left(\frac{\partial \mathrm{w}}{\partial \mathrm{t}}\right)^{2} \mathrm{dz}+\frac{1}{2} \mathrm{~m} \int_{0}^{1}\left(\frac{\mathrm{dw}}{\mathrm{dt}}\right)^{2} \mathrm{dz}
$$

Where $\mathrm{E}, \mathrm{G}, 1, \rho, \mathrm{m}$ and $\mathrm{F}$ denote modulus of elasticity, modulus of elasticity in shear, nonlinearity coefficient, density, mass of load per unit length and cross sectional area, respectively. The principle of Hamilton for this beam is as follow:

$$
\begin{aligned}
& \mathrm{H}=\int_{\mathrm{t}_{1}}^{\mathrm{t}_{2}}(\Pi-\mathrm{ki}) \mathrm{dt}=\int_{\mathrm{t}_{1}}^{\mathrm{t}_{2}} \int_{0}^{1}\left[\frac{1}{2} \mathrm{EI}_{0}\left(\frac{\partial^{2} \mathrm{w}}{\partial \mathrm{z}^{2}}\right)^{2}-\frac{1}{54} \mathrm{l}_{2} \frac{\mathrm{E}^{4}}{\mathrm{G}^{3}} \mathrm{I}_{1}\right. \\
& \left.\left(\frac{\partial^{2} \mathrm{w}}{\partial \mathrm{Z}^{2}}\right)^{4}-\frac{1}{2} \rho \mathrm{F}\left(\frac{\partial \mathrm{w}}{\partial \mathrm{t}}\right)^{2}-\frac{1}{2} \mathrm{~m}\left(\frac{\mathrm{dw}}{\mathrm{dt}}\right)^{2}\right] \mathrm{dtdz}
\end{aligned}
$$

by considering, $\frac{d w}{d t}=\frac{\partial w}{\partial t}+v \frac{\partial w}{\partial z}$ and Euler equation:

$$
\frac{\partial^{2}}{\partial \mathrm{z}^{2}}\left(\frac{\partial \mathrm{L}}{\partial \mathrm{u}}\right)-\frac{\partial}{\partial \mathrm{t}}\left(\frac{\partial \mathrm{L}}{\partial \mathrm{k}}\right)-\frac{\partial}{\partial \mathrm{z}}\left(\frac{\partial \mathrm{L}}{\partial \mathrm{i}}\right)=0
$$


where, $\mathrm{u}=\frac{\partial^{2} \mathrm{w}}{\partial \mathrm{z}^{2}}, \mathrm{k}=\frac{\partial \mathrm{w}}{\partial \mathrm{t}}, \mathrm{i}=\frac{\partial \mathrm{w}}{\partial \mathrm{z}}$ by considering Eq. (43) and Eq. (42) and further simplification the differential motion equation can be written as:

$$
\begin{aligned}
& \frac{\pi^{4}}{1^{4}} \frac{\partial^{4} w}{\partial \zeta^{4}}+\frac{\pi^{2} m v^{2}}{1^{2} E I_{0}} \frac{\partial^{2} w}{\partial \zeta^{2}}+\frac{\omega^{2}(\rho F+m)}{E I_{0}} \frac{\partial^{2} w}{\partial \tau^{2}}= \\
& \frac{2}{9} 1_{2} \frac{E^{3}}{G^{3}} \frac{I_{1}}{I_{0}} \frac{\pi^{8}}{1^{8}} \frac{\partial^{2} w}{\partial \zeta^{2}}\left[2\left(\frac{\partial^{3} w}{\partial \zeta^{3}}\right)^{2}+\frac{\partial^{2} w}{\partial \zeta^{2}} \frac{\partial^{4} w}{\partial \zeta^{4}}\right]
\end{aligned}
$$

Where, As solving of the Eq. (44) is difficult the consecutive approximated method is used. Furtheremore, to make the solving procedure easier, it is assumed at linear state:

$$
\mathrm{w}_{0}=\mathrm{Q}_{0} \operatorname{Sink} \zeta \cdot \operatorname{Cos} \tau
$$

where: $\mathrm{Q}_{0}$, Is amplitude of vibration of beam at linear state.

If Eq. (45) is substituted at right side of Eq. (44) and is simplified, the following equation is derived:

$$
\begin{aligned}
& \frac{\pi^{4}}{1^{4}} \frac{\partial^{4} w}{\partial \xi^{4}}+\frac{\pi^{4} m v^{2}}{1^{4} \mathrm{II}_{0}} \frac{\partial^{2} \mathrm{w}}{\partial \xi^{2}}+\frac{\omega^{2}(\rho \mathrm{F}+\mathrm{m})}{\mathrm{EI}_{0}} \frac{\partial^{2} \mathrm{w}}{\partial \tau^{2}}= \\
& \frac{1}{72} \mathrm{l}_{2} \frac{\mathrm{E}^{3}}{\mathrm{G}^{3}} \frac{\mathrm{I}_{1}}{\mathrm{I}_{0}} \frac{\pi^{8} \mathrm{k}^{8}}{\mathrm{l}^{8}} \mathrm{Q}_{0}^{3}(3 \operatorname{Sin} \mathrm{k} \xi \cdot \operatorname{Cos} \tau+\operatorname{Sin} \mathrm{k} \xi \cdot \operatorname{Cos} 3 \tau) \\
& -9 \operatorname{Sin} 3 \mathrm{k} \xi \cdot \operatorname{Cos} \tau-3 \operatorname{Sin} 3 \mathrm{k} \xi \cdot \operatorname{Cos} 3 \tau)
\end{aligned}
$$

Private solving of Eq. (11) is defined as follow:

$$
\begin{aligned}
& \mathrm{w}(\zeta, \tau)=\mathrm{a}_{1} \operatorname{Sink} \zeta \cdot \operatorname{Cos} \tau+\mathrm{a}_{2} \operatorname{Sink} \zeta \cdot \operatorname{Cos} 3 \tau+ \\
& \mathrm{a}_{3} \operatorname{Sin} 3 \mathrm{k} \zeta \cdot \operatorname{Cos} \tau+\mathrm{a}_{4} \operatorname{Sin} 3 \mathrm{k} \zeta \cdot \operatorname{Cos} 3 \tau
\end{aligned}
$$

Where $a_{1}, a_{2}, a_{3}, a_{4}$ are constant coefficients, by substitution Eq. (47) into Eq. (46) and comparing the same coefficients $\operatorname{Sink} \xi \operatorname{Cos} \tau, \mathrm{a}_{1}, \mathrm{a}_{2}, \mathrm{a}_{3}, \mathrm{a}_{4}$ and $\omega$ are obtained, which are as follows:

$$
\begin{aligned}
& \frac{\pi^{4} \mathrm{k}^{4}}{\ell^{4}} \mathrm{a}_{1}+\frac{\pi^{2} \mathrm{k}^{2} \mathrm{mv}^{2}}{\ell^{2} \mathrm{EI}} \mathrm{a}_{1}- \\
& \frac{\omega^{2}(\rho \mathrm{F}+\mathrm{m})}{\mathrm{EI}}=\frac{1}{24} \ell_{2} \frac{\mathrm{E}^{3}}{\mathrm{C}^{3}} \frac{\mathrm{I}_{1}}{\mathrm{I}_{0}} \frac{\pi^{8} \mathrm{k}^{8}}{\ell^{8}} \mathrm{Q}_{0}^{3} \\
& \frac{\pi^{4} \mathrm{k}^{4}}{\ell^{4}} \mathrm{a}_{2}+\frac{\pi^{2} \mathrm{k}^{2} \mathrm{mv}^{2}}{\ell^{2} \mathrm{EI}_{\circ}} \mathrm{a}_{2}-9 \frac{\omega^{2}(\rho \mathrm{F}+\mathrm{m})}{\mathrm{EI} \mathrm{I}_{\circ}} \\
& =\frac{1}{72} \ell_{2} \frac{\mathrm{E}^{3}}{\mathrm{C}^{3}} \frac{\mathrm{I}_{1}}{\mathrm{I}_{0}} \frac{\pi^{8} \mathrm{k}^{8}}{\ell^{8}} \mathrm{Q}_{0}^{3}
\end{aligned}
$$

$$
\begin{aligned}
& 81 \frac{\pi^{4} \mathrm{k}^{4}}{\ell^{4}} \mathrm{a}_{3}-9 \frac{\pi^{2} \mathrm{k}^{2} \mathrm{mv}^{2}}{\ell^{2} \mathrm{EI}} \mathrm{a}_{3}- \\
& \frac{\omega^{2}(\rho \mathrm{F}+\mathrm{m})}{\mathrm{EI}} \mathrm{a}_{3}=-\frac{1}{8} \ell_{2} \frac{\mathrm{E}^{3}}{\mathrm{C}^{3}} \frac{\mathrm{I}_{1}}{\mathrm{I}_{0}} \frac{\pi^{8} \mathrm{k}^{8}}{\ell^{8}} \mathrm{Q}_{0}^{3} \\
& 81 \frac{\pi^{4} \mathrm{k}^{4}}{\ell^{4}} \mathrm{a}_{4}-9 \frac{\pi^{2} \mathrm{k}^{2} \mathrm{mv}^{2}}{\ell^{2} \mathrm{EI}} \mathrm{a}_{4}-9 \frac{\omega^{2}(\rho \mathrm{F}+\mathrm{m})}{\mathrm{EI}} \\
& \mathrm{a}_{4}=-\frac{1}{24} \ell_{2} \frac{\mathrm{E}^{3}}{\mathrm{C}^{3}} \frac{\mathrm{I}_{1}}{\mathrm{I}_{0}} \frac{\pi^{8} \mathrm{k}^{8}}{\ell^{8}} Q_{0}^{3}
\end{aligned}
$$

Thus circular frequency of system $\omega$ is obtained:

$$
\begin{aligned}
& \omega^{2}=\frac{\mathrm{EI}_{0}}{(\rho \mathrm{F}+\mathrm{m})} \cdot \frac{\pi^{2} \mathrm{k}^{2}}{1^{2}}\left(\frac{\pi^{2} \mathrm{k}^{2}}{1^{2}}-\frac{\mathrm{mv}^{2}}{\mathrm{EI}_{0}}\right) \\
& \left(1-\frac{1}{24} \mathrm{l}_{2} \frac{\mathrm{E}^{4}}{\mathrm{G}^{3}} \mathrm{I}_{1} \frac{\pi^{6} \mathrm{k}^{6}}{\mathrm{l}^{4}} \mathrm{Q}_{0}^{2} \frac{1}{\pi^{2} \mathrm{k}^{2} \mathrm{EI}_{0}-\mathrm{mv}^{2} \mathrm{l}^{2}}\right)
\end{aligned}
$$

The critical velocity is derived by considering the criteria $\omega=0.0$

$$
\mathrm{V}_{\mathrm{cr}}=\frac{\pi \mathrm{k}}{1} \sqrt{\frac{\mathrm{EI}_{0}}{\mathrm{~m}}\left(1-\frac{1}{24} \mathrm{l}_{2} \frac{\mathrm{E}^{3}}{\mathrm{G}^{3}} \frac{\mathrm{I}}{\mathrm{I}_{0}} \frac{\pi^{4} \mathrm{k}^{4}}{\mathrm{l}^{4}} \mathrm{Q}_{0}^{2}\right)}
$$

If $l_{2}=0.0$ the critical velocity is obtained at linear state, $\mathrm{V}_{\mathrm{cr}}=\frac{\pi \mathrm{k}}{1} \sqrt{\frac{\mathrm{EI}_{0}}{\mathrm{~m}}}$

If at Eq. (52), $\mathrm{m}=0.0$ that is the load is out of beam:

$$
\omega=\frac{\pi^{2} k^{2}}{l^{2}} \sqrt{\frac{E I_{0}}{\rho \mathrm{F}}\left(1-\frac{1}{24} l_{2} \frac{E^{3}}{G^{3}} \frac{I_{1}}{I_{0}} \frac{\pi^{4} k^{4}}{l^{4}} Q_{0}^{2}\right)}
$$

$\omega$ is the circular frequency at free vibration at physical nonlinear. It is seen from Eq. (52) the circular frequency of system depends on nonlinearity of material and the velocity of load.

To understand the analysis obtained here an example is presented in this section. For the assumed beam shown in Fig. (7) the parameters used in studied equation are as what follows:

$\mathrm{E}=2.1 \times 10^{5} \mathrm{Mpa}$

$\mathrm{G}=0.87 \times 10^{5} \mathrm{Mpa}$

$\mathrm{l}_{2}=0.085 \times 10^{6}$

$\mathrm{q}=\mathrm{mg}=20 \mathrm{KN} / \mathrm{m}$ (unit weight of load)

$\mathrm{P}=\rho \mathrm{fg}=0.66 \mathrm{KN} / \mathrm{m}$ (unit weight of beam)

$\mathrm{I}_{0}=1.51 \times 10^{-3} \mathrm{~m}^{4}$

$\mathrm{I}_{1}=1.3 \times 10^{-4} \mathrm{~m}^{6}$

$\mathrm{L}=12 \mathrm{~m}$ 


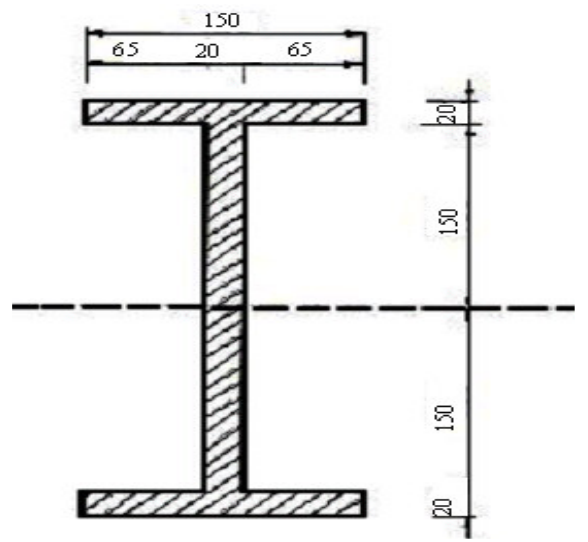

Fig. 7: Section of beam

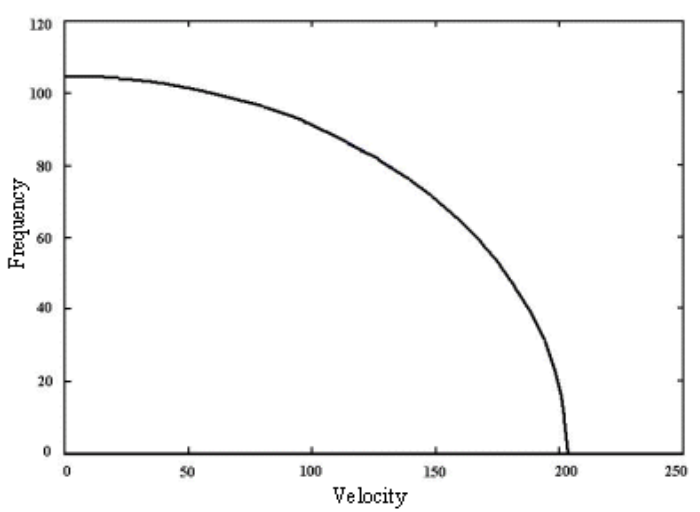

Fig. 8: Frequency-velocity curve

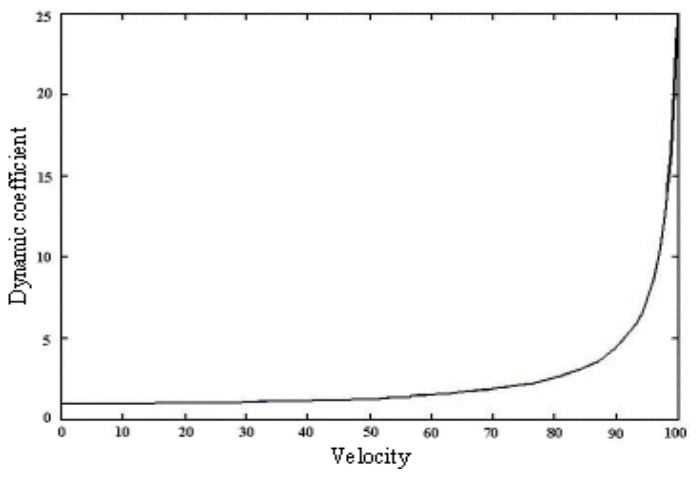

Fig.9. Dynamic coefficient-velocity curve

Circular frequency is obtained from Eq. (52) and plotted in Fig. (8).

The critical velocity is obtained from Eq. (53): $\mathrm{Vcr}=103.044 \mathrm{~m} \mathrm{sec}{ }^{-1}$. The dynamic coefficient (Yd/Ys) at the middle point of beam is derived from Eq. (52) and plotted in Fig. 9.

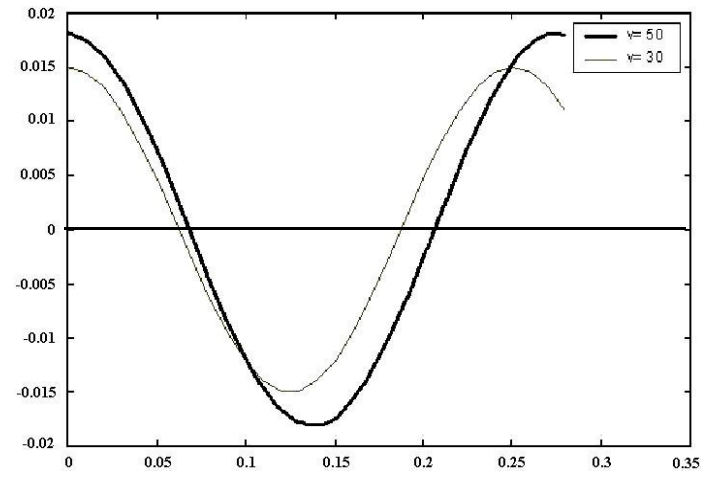

Fig. 10: Amplitude of Vibration at the middle of beam during vibration period

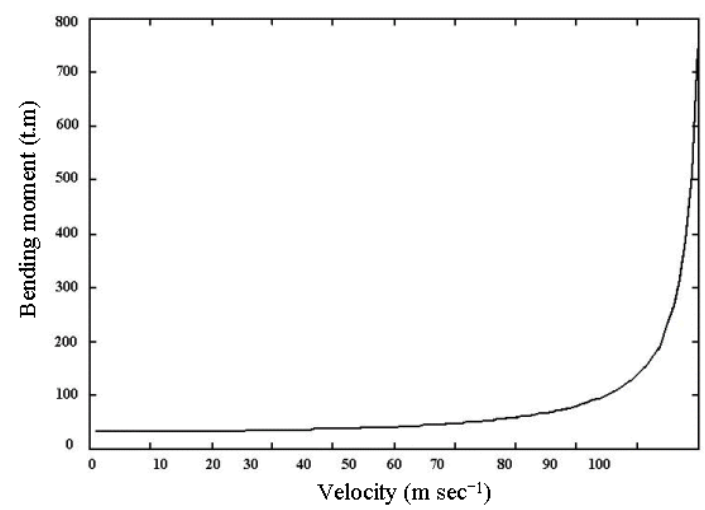

Fig.11: Bending moment-velocity curve

Diagram of motion at interval of a period is showed as below. ( for $\mathrm{v}=30 \mathrm{~m} \mathrm{sec}^{-1}, 50 \mathrm{~m} \mathrm{sec}^{-1}$ ) Fig. 10.

The bending moment at the middle point $(\mathrm{a}=\mathrm{L} / 2)$ Fig. 11.

\section{CONCLUSIONS}

The effect of material nonlinearity on the response parameters of bridge under concentrated and distributed moving loads are investigated analytically. The Hamiltonian principles and Euler's equations employed to found the nonlinear vibration equation of the system. The Fourier series is used to decompose the deflection as a multiplication of functions in time and space. The resulting equation in time is the well known Duffing's equation. Solving the Duffing equation by perturbation method the response parameters of the system is evaluated. In the case of concentrated moving load and linear material, theoretically with increasing the speed of the moving load resonance might happen. However 
Am. J. Applied Sci., 6 (2): 224-232, 2009

considering the material nonlinearity, resonance doesn't happen and the internal forces will have definite values. Taking into account the material nonlinearity the internal forces for velocities blew critical velocity reduces as much as 10-15 percent in comparison with the linear case. Using the results dynamic amplification factors is calculated for the system. Increasing the material nonlinearity, results in decreasing in the value of vibration amplitude. In the case of distributed continuous moving loads using analytical solution, vibration frequency and the dynamic amplification factors and bending moment are evaluated for different velocities, blew critical velocity. Analysis shows that the more is the speed of the moving load, the more is the amplitude of the vibration.

\section{NOTATION}

\begin{tabular}{|c|c|}
\hline A & $=$ External work of the moving load \\
\hline$\alpha$ & $\begin{array}{l}=\text { The distance of the concentrated load } \\
\text { from the support }\end{array}$ \\
\hline $\mathrm{E}$ & $=$ Module of elasticity \\
\hline $\mathrm{F}$ & $=$ An area of the section \\
\hline G & $=$ Sheer elastic module \\
\hline $\mathrm{H}$ & $=$ Hamilton Principle \\
\hline $\mathbf{J}_{0}$ & $=$ Moment of inertia \\
\hline $\mathrm{J}_{1}$ & $=\iint x^{4} d x d y$ \\
\hline K & $=$ Volume contraction \\
\hline $\mathrm{K}\left(\sigma_{0}\right)$ & $=$ Average stress function \\
\hline $\mathrm{Ki}$ & $=$ Kinetic energy \\
\hline $\mathrm{L}$ & $=$ The span of the beam \\
\hline $1\left(\mathrm{t}_{0}^{2}\right)$ & $=$ Sheer stress function \\
\hline $1_{2}$ & $=$ Nonlinear coefficient \\
\hline $\mathrm{p}(\xi)$ & $=$ Coordinate function \\
\hline $\mathrm{P}$ & $=$ Concentrated load \\
\hline $\mathrm{p}(\mathrm{z})$ & $=$ The head vibration made of the beam \\
\hline $\mathrm{q}(\tau)$ & $=$ Generalized function \\
\hline$q(z, t)$ & $=$ Equation distributed load \\
\hline $\mathrm{w}(\mathrm{z}, \mathrm{t})$ & $=$ Deformation of the beam \\
\hline $\mathrm{X}$ & 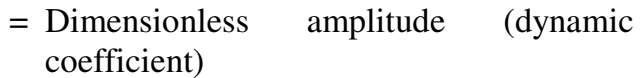 \\
\hline
\end{tabular}

$$
\begin{array}{ll}
\mathrm{Z} & =\text { A distance of any point from the support } \\
\sigma & =\text { Stress } \\
\sigma_{0} & =\text { Average stress } \\
\sigma_{\mathrm{X}}, \sigma_{\mathrm{Y}}, \sigma_{\mathrm{Z}} & =\text { Original stress } \\
\varepsilon & =\text { Strain } \\
\varepsilon_{\mathrm{ij}} & =\text { Three-dimensional strain } \\
\rho & =\text { Density } \\
\pi & =\text { Potential energy } \\
\omega_{0} & =\text { Circular frequency } \\
\theta & =\text { Circular frequency of load } \\
\mathrm{V} & =\text { Velocity } \\
& \text { REFERENCES }
\end{array}
$$

\section{REFERENCES}

1. Kauderer, H., 1961. Nonlinear Mechanic. Moscow, Foreign Publish Literature.

2. Babakov, I.M., 1968. Theory of Vibration. Moscow, Government Publisher.

3. Mardani, E., R. Garibov, and A. Isayev, 1996. Physical nonlinear analysis of a beam under moving load. The Second international Conference on Bridges, Tehran, Iran, pp: 20-25.

4. Mardani, E., and R.T. Garibov, 1997. Physical nonlinear analysis of a prismatic beam under moving continuous distributed load. Sci. Works Struct. Mech., Baku, ELM, 7 (2): 70-74.

5. Glushkov, G., 1974. Engineering Method for Analyzing Strength and Rigidity. Moscow, Scientific and Technical literature.

6. Kesiliev, V.A., 1969. Structural Mechanic. Moscow, Scientific and Technical Literature.

7. Panovko, Y.Q., and Y.Y. Qubanova, 1987. Vibration and Stability in Elastic Systems. Moscow, Physics Mathematics Literature.

8. Qaribov, R., and N. Hasanov, 2001. Analysis of deformation of prismatic beams made of physical nonlinear material under impulse loads. Sci. Works Struct. Mech. Baku, ELM, 11: 178-180.

9. Qaribov, R., 1987. An analysis of pure deformation of a prismatic beam made of physical nonlinear material. Seventh Scientific Conference of Young Scientists. Baku, pp: 1-4. 